\title{
COLAPSO DO POPULISMO E REGIME MILITAR NO BRASIL
}

\author{
Enrique Ricardo Lewandowski \\ Professor Associado do Departamento de Direito do Estado da FDUSP \\ Desembargador do Tribunal de Justiça do Estado de São Paulo
}

\begin{abstract}
Resumo:
O artigo trata da crise social e política que levou à deposição do presidente João Goulart pelas Forças Armadas, dando início a um longo ciclo de governos militares. Analisa também os principais instrumentos jurídicos que deram sustentação ao regime militar instalado no País depois de 1964.
\end{abstract}

\begin{abstract}
:
The article deals with the social and political crisis that caused the deposition of president João Goulart by the Armed Forces, initiating a long cycle of military governments. It also analyses the main legal instruments that gave support to the military regime installed in the country after 1964 .
\end{abstract}

Unitermos: populismo; regime militar; ato institucional.

Sumário:

1. Antecedentes do movimento

2. O colapso do populismo

3. As Reformas de Base

4. O estopim do golpe

5. A deposição de Goulart

6. O primeiro Ato Institucional

7. A consolidação do regime

8. O golpe dentro do golpe 


\section{Antecedentes do movimento}

O movimento político-militar de 31 de março de 1964, que derrubou o presidente João Goulart, iniciando um longo ciclo de governos castrenses, embora tenha como causa imediata a agitação social desencadeada pela tentativa de implantar no País as chamadas Reformas de Base, deita raízes no colapso do populismo.

O populismo constitui um fenômeno social e político que ocorre, de forma típica, na passagem de uma sociedade tradicional, arcaica ou rural, para uma sociedade moderna, urbana ou industrial. Consiste, basicamente, numa aliança política entre setores sociais urbanos. Trata-se, antes de mais nada, de um modo característico de organização da sociedade e de estruturação do poder.'

Tal fenômeno manifestou-se, de modo semelhante e praticamente simultâneo, por volta da terceira década do século XX, em quase toda a América Latina, coincidindo sempre com o fortalecimento do empresariado nacional e dos trabalhadores urbanos gerado pelo processo de industrialização. Para designar esse movimento que, como regra, vinha associado ao surgimento de lideranças carismáticas, que o dirigiam, manipulando as massas populares em proveito de seus projetos políticos pessoais, os analistas têm empregado as seguintes expressões: battlismo no Uruguai; yrigoyenismo e peronismo na Argentina; varguismo e trabalhismo no Brasil; velasquismo no Equador; odrirismo e aprismo no Peru; gaitanismo na Colômbia; perezgimenismo na Venezuela; marinismo em Porto Rico; callismo e cardenismo no México. ${ }^{2}$

No Brasil, o populismo iniciou-se com a ascensão de Getúlio Vargas ao governo e perdurou até a derrubada de João Goulart. Surgiu como resultante da decadência social e econômica da oligarquia agrário-mercantil que, de forma hegemônica, detinha o poder político até o início do processo de industrialização do

1. Dos estudos feitos sobre o assunto, no Brasil, destacam-se, por sua especificidade, os trabalhos de Octavio Ianni, O Colapso do Populismo no Brasil, Rio de Janeiro, Civilização Brasileira, $3^{\mathrm{a}}$ ed., 1975; A Formação do Estado Populista na América Latina, Rio de Janeiro, Civilização Brasileira 1975; e, ainda, de Francisco Correa Weffort, O Populismo na Política Brasileira, Rio de Janeiro, Paz e Terra, 1978.

2. Cf. Octavio Ianni, A Formação do Estado Populista na América Latina, cit., p. 7. 
País, desencadeado nos anos 30 , em conseqüência do mecanismo de substituição de importações. ${ }^{3}$

A continuidade do populismo somente foi possível na medida em que, até o final da década de 50 , a substituição de importações manteve o seu potencial de expansão, garantindo uma performance positiva ao sistema econômico. De fato, durante o período populista, houve um incremento do salário real dos trabalhadores, um aumento da participação dos assalariados no processo produtivo, uma multiplicação das oportunidades de emprego e uma ampliação do nível geral de renda. $^{4}$

2. O colapso do populismo

Hélio Jaguaribe e Octavio Ianni indicam, de forma coincidente, o final do governo de Juscelino Kubitscheck como o início do colapso do populismo. Para o primeiro, a partir desse momento, "esgotou-se a capacidade, por parte do modelo econômico que presidiu ao populismo e à democracia populista, de assegurar a continuidade do crescimento econômico e de prosseguir nas etapas subseqüentes do aprofundamento da revolução industrial brasileira", acrescendo que "os ganhos de produtividade, que eram redistribuidos, embora desigualmente, pelos vários setores que compunham a aliança populista, deixaram de ser redistribuidos, porque deixaram de existir". ${ }^{5}$ O segundo explica que, por volta de 1962, esgotou-se um longo processo de expansão econômica, registrando-se, depois dessa data, uma queda na taxa de desenvolvimento e, após 1963, uma espiral inflacionária de conotações patológicas para o sistema. ${ }^{6}$

3. O processo de substituição de importações desenvolveu-se a partir do colapso do sistema financeiro internacional, que se seguiu ao famoso crack da Bolsa de Nova York, em 1929. Consistiu, basicamente, como deflui da própria expressão, no processo de substituição de mercadorias industrializadas, importadas com divisas provenientes da exportação de produtos agrícolas, por manufaturas nacionais. Esse processo, desencadeado a partir da transferência de capitais da lavoura para a indústria, acarretou, paradoxalmente, o desenvolvimento de uma burguesia industrial e de um proletariado urbano, que representavam, em grande medida, a antitese política das classes tradicionalmente ligadas à terra.

4. Cf. Hélio Jaguaribe, "O Modelo Político e a Estrutura Econômica-Social Brasileira", in Encontros com a Civilização Brasileira, Rio de Janeiro, n. 4, outubro de 1978, p. 131.

5. Idem, pp. 132-133.

6. Cf. Octavio Ianni, O Colapso do Populismo no Brasil, cit., p. 208. 
Nesse contexto, as massas trabalhadoras passaram a exigir aumentos salariais cada vez mais freqüentes, entrando numa luta reivindicatória praticamente ininterrupta, visando a evitar o rebaixamento dos padrões salariais. ${ }^{7}$ Esse embate, que se politizou e ganhou as ruas, levou ao fortalecimento das organizações sindicais e à intensificação do relacionamento do operariado com os partidos populistas e de esquerda. ${ }^{8}$

Para os estudiosos dessa fase, as causas da crise devem ser procuradas no esgotamento do processo de substituição de importações, responsável pela industrialização do País. Hélio Jaguaribe, Bresser Pereira e outros assinalam que as reduzidas dimensões do mercado consumidor nacional da época não permitiram que esse processo se mantivesse indefinidamente. Assim, a partir de determinado momento, mais precisamente, depois do Programa de Metas de Juscelino Kubitscheck, o crescimento econômico viu-se bloqueado pela inexistência de capitais necessários à expansão do setor industrial. ${ }^{9}$

Sobreveio, então, uma estagnação econômica que, no dizer de Jaguaribe, provocou um agudizamento das tensões sociais e "um realinhamento de solidariedades" ${ }^{10}$ Isso porque o êxito do pacto populista repousava, fundamentalmente, na participação, ainda que desigual, das diferentes classes sociais nas vantagens materiais do sistema, mas que, com a crise econômica, deixou de ocorrer.

Para superar o impasse, cujos reflexos colocavam em xeque as bases de sustentação do regime, o Governo Goulart enveredou, com o insucesso conhecido, pelo caminho das reformas estruturais. A tentativa de promover as denominadas Reformas de Base, todavia, ao invés de apaziguar os ânimos, acirrou o conflito social latente, precipitando a eclosão do golpe militar de 1964.

7. Idem, p. 209.

8. Ibidem, loc. cit.

9. Cf. Hélio Jaguaribe, "O Modelo Político e a Estrutura Econômica-Social Brasileira", cit., pp. 132 e ss., e Brasil: Crise e Alternativas, Rio de Janeiro, Zahar, 1974, pp. 30 e ss.; Bresser Pereira, $O$ Estado e o Subdesenvolvimento Industrializado: Esboço de uma Economia Política Periférica, São Paulo, Brasiliense, 1977, pp. 126 e ss.; e Celso Furtado, Dialética do Desenvolvimento, Rio de Janeiro, Fundo de Cultura, $2^{a}$ ed., 1964, pp. 113 e ss.

10. "O Modelo Politico e a Estrutura Econômica-Social Brasileira", cit., p. 135. 


\section{As Reformas de Base}

O primeiro passo das Reformas de Base foi anunciado no famoso comício do dia 13 de março de 1964, no Rio de Janeiro, perante uma multidão de aproximadamente 200 mil pessoas, arregimentadas por sindicatos aliados ao governo e outras organizações ligadas à cúpula dirigente. Nessa ocasião, Goulart, num discurso inflamado, afirmou que "governo nenhum, por maior que seja o seu esforço e até seu sacrifício, poderá enfrentar o monstro inflacionário que devora salários e que inquieta o povo se não forem realizadas reformas de estrutura exigidas pelo povo e reclamadas pela nação" anunciando, em seguida, a execução de medidas de impacto, por meio de decretos, tais como a encampação de refinarias particulares, o tabelamento de aluguéis de imóveis desocupados e a expropriação de terras valorizadas por investimentos públicos, quais sejam, aquelas localizadas às margens dos eixos rodoviários e ferroviários e dos açudes, bem como de áreas inexploradas que pudessem tornar-se produtivas."

Além disso, pediu publicamente o apoio popular à mensagem que remeteria ao Congresso Nacional contendo, em suma, as seguintes proposições: reforma agrária, com a alteração do artigo da Constituição que previa a indenização prévia em dinheiro das terras expropriadas; reforma política, com a extensão do direito de voto aos analfabetos e praças de pré, introduzindo o princípio segundo o qual "os alistáveis devem ser elegíveis"; reforma universitária, garantindo plena liberdade de ensino e abolindo a vitaliciedade de cátedra; reforma constitucional para outorgar maiores poderes ao presidente da República; e, por fím, a convocação de uma consulta ao povo objetivando referendar as Reformas de Base. ${ }^{12}$

Dentro do contexto político de então, a tentativa de apaziguar as massas populares, através dessas medidas, representou uma guinada ideológica à esquerda, aos olhos das camadas sociais dominantes. É difícil, contudo, ainda hoje, avaliar se as medidas anunciadas por Goulart constituíam simples reformas ou se objetivavam a alteração revolucionária das instituições. A verdade é que o grande

11. V. discurso de Goulart publicado na integra por Carlos Castello Branco, em Introdução à Revolução de 1964: A Queda de João Goulart, $2^{\circ}$ tomo, Rio de Janeiro, Artenova, 1965, p. 264.

12. Idem, ibidem; v. também Moniz Bandeira, O Governo João Goulart: As lutas sociais no Brasil, Rio de Janeiro, Civilização Brasileira, 2' ed., 1977, pp. 163-164; v., ainda, sobre a amplitude das medidas Cibilis da Rocha Viana, Reformas de Base e a Politica Nacionalista de Desenvolvimento: De Getúlio a Jango, Rio de Janeiro, Civilização Brasileira, 1980. 
compromisso social em que se apoiava o regime, em face da crise econômica, de um lado, e da tentativa de implantação das Reformas de Base, de outro, viu-se, de repente, condenado por todas as forças que o compunham. ${ }^{13}$

4. O estopim do golpe

O comício do dia 13 de março marcou o começo do fím do Governo Goulart e, com ele, o do regime populista. O presidente, empolgado com as manifestações de apoio das massas, em grande medida artificialmente orquestradas pelos sindicatos, partidos políticos e, até, órgãos governamentais, passou a distanciar-se, cada vez mais, de seus colaboradores moderados, aproximando-se de forma progressiva da esquerda radical. ${ }^{14}$

Essa atitude de Goulart foi responsável pela colocação do estamento militar em franca oposição ao governo. Depois de uma série de provocações, dois fatos, além do politicamente desastrado comício em que foram anunciadas as Reformas de Base, precipitaram o golpe institucional deflagrado no dia 31 de março, unindo os militares e as classes alta e média contra o regime: o motim dos marinheiros, ocorrido entre 25 e 29 de março, e a reunião dos sargentos, realizada no Automóvel Clube, no dia 30 subseqüente.

$\mathrm{Na}$ verdade, a situação política, a partir do dia 13, começou a deteriorar-se rapidamente. Em São Paulo, no dia 19, organizou-se, como resposta ao comício do Rio de Janeiro, sob os auspícios de várias entidades femininas de classe média, inclusive religiosas, a Marcha da Familia com Deus pela Liberdade, que reuniu cerca de 500 mil pessoas numa passeata da Praça da República à Praça da Sé. Apesar do sucesso da Marcha e do impacto político que causou, os militares ainda relutavam em participar abertamente de um movimento armado contra o presidente. $^{15}$

Logo em seguida, porém, eclodiu o motim dos marinheiros, que engajou definitivamente os militares nas articulações para a deposição de Goulart. A rebelião teve origem na prisão e no desligamento, por determinação do ministro da

13. Cf.Weffort, op. cit., p. 78.

14. Cf. Thomas Skidmore, Brasil: De Getúlio Vargas a Castello Branco (1930-1964), Rio de Janeiro, Paz e Terra, pp. 344 e ss.

15. Idem, ibidem. 
Marinha, de alguns marujos envolvidos em manifestações políticas e atos de indisciplina. Poucos dias depois das punições, ou seja, no dia 25 de março, aproximadamente 2 mil marinheiros reuniram-se na sede do Sindicato dos Trabalhadores Metalúrgicos, no Rio de Janeiro, exigindo a revogação das sanções e 0 afastamento do ministro. ${ }^{16}$

As autoridades da Marinha, surpresas com a audácia e a politização do movimento, não toleraram a provocação e enviaram, contra os marinheiros sublevados, tropas do Corpo de Fuzileiros Navais que, comandadas por um almirante comprometido com as posições radicais do governo, voltaram ao quartel sem cumprir a missão. Alguns fuzileiros, inclusive, depuseram suas armas, juntandose aos insurretos. ${ }^{17}$

Diante dessa crise sem precedentes, que começou a ampliar-se, alastrando-se para outras unidades da Armada, o presidente, ao invés de prestigiar o seu ministro da Marinha, preferiu demití-lo, substituindo-o por um almirante da Reserva, indicado por sindicatos e pelos marinheiros sublevados. ${ }^{18}$

A reação das Forças Armadas ao gesto presidencial, recebido como uma afronta pelas lideranças militares, não se fez esperar. Temendo a dissolução de suas corporações, tradicionalmente fundadas na hierarquia e na disciplina, especialmente na estrita profissionalização de seus membros, ou seja, no seu distanciamento das disputas político-partidárias, ao menos no que tange aos escalões inferiores, os principais chefes das três Armas emitiram uma série de manifestos. Nesses pronunciamentos, assumiram posições francamente hostis à atuação do governo, indicando a disposição de se lançarem à ação.

A tônica desses manifestos deixava entrever que a adesão das Forças Armadas ao movimento oposicionista, condição essencial para o desencadeamento de um golpe bem-sucedido contra o governo, já estava garantida àquela altura dos acontecimentos. Faltava, contudo, um estopim, uma pequena fagulha, para que o movimento fosse deflagrado. Esse estopim consistiu na reunião de quase mil

16. Discurso publicado na integra por Glauco Carneiro, História das Revoluções Brasileiras, $2^{\circ}$ v., Rio de Janeiro, O Cruzeiro, 1965, pp. 600-602.

17. V. Skidmore, op. cit., pp. 344 e ss.; v. também Alfred Stepan, Os Militares na Política: Mudanças de Padrões na Vida Brasileira, Rio de Janeiro, Arte Nova, 1975, pp. 138 e ss.; Peter Flynn, Brazil: A Political Analisys, London, Ernest Ben Boulder-Westview Press, 1978, pp. 280 e ss.; Glauco Carneiro, op. cit., pp. 552 e ss.

18. Idem, ibidem. 
sargentos, sediados em unidades do Rio de Janeiro, no dia 30 de março, no auditório do Automóvel Clube, em comemoração ao aniversário da Associação dos Suboficiais e Sargentos da Polícia Militar.

Compareceram ao evento, transmitido em cadeia de rádio e televisão para todo o País, além do presidente da República, várias autoridades governamentais, inclusive militares ligados a Goulart. Diversos oradores sucederamse na tribuna, proferindo discursos veementes, vazados numa forma polêmica e com um forte conteúdo ideológico, manifestando apoio às Reformas de Base e aos revoltosos da Marinha, cujo movimento já se alastrava para os quartéis das outras Armas.

Após a reunião no Automóvel Clube, muitos militares que, até aquele momento, não estavam ainda plenamente convencidos de tomar parte na conspiração contra o governo, mudaram de idéia, especialmente depois de ouvir a inflamada fala do presidente. Um importante chefe castrense que relutou até a última hora foi, por exemplo, o general Amaury Kruel, comandante do II Exército, sediado em São Paulo. ${ }^{19}$ No final, porém, para todos os militares, o esprit de corps e o instinto de sobrevivência corporativo falou mais alto do que a fidelidade formal que dedicavam às autoridades constituídas.

\section{A deposição de Goulart}

A seqüência dos acontecimentos é hoje sobejamente conhecida, fazendo parte da História. Recorda-se, todavia, que as tropas insurretas que marcharam de Minas Gerais e de São Paulo sobre o Rio de Janeiro não encontraram qualquer resistência por parte das forças leais ao governo. Na realidade, ao invés de choques entre exércitos antagônicos, registraram-se adesões e confraternizações: $O$ mesmo ocorreu por todo o País, onde as principais guarnições militares foram dominadas sem embaraços. Por toda parte, políticos oposicionistas, lideranças civis e empresários colaboraram para o sucesso do putsch. $^{20}$

Segundo Skidmore, "o Governo Goulart caiu tão rapidamente que até os 'revolucionários' ficaram surpresos", lembrando que, ao invés de "armar uma

19. Idem, ibidem.

20. V. "Quatro dias que abalaram o País", Isto É,03.04.96, n. 1.383, pp. 22-26. 
resistência no Rio de Janeiro, ou em Brasília, ou no Rio Grande do Sul, Goulart fugiu do Brasil, deixando seus perplexos partidários isolados ..." 21

A bem da verdade, contudo, antes de deixar o País, rumo ao Uruguai, o presidente deposto reuniu-se em Porto Alegre, no Rio Grande do Sul, com alguns oficiais para examinar a situação militar. Nessa ocasião, o general Floriano Machado, da $3^{\text {a }}$ Região Militar, convenceu o presidente a desistir da luta, asseverando o seguinte: "Sinto ter de dizer-lhe estas palavras, que são, entretanto, uma impressão sincera, fundada em razões muito fortes. $V$ Exa. não deve pensar em resistência, nas condições atuais. Qualquer outro tipo de luta (já não há condições para a de tropas regulares), será guerra civil, será investir contra o Exército, que está unido e disciplinado" 22

A sucessão de Goulart, surpreendentemente, correu de forma suave, visto que os vencedores optaram por um candidato de compromisso, o general Humberto de Alencar Castello Branco, militar de prestígio entre os colegas de farda e também bem-aceito pelas lideranças civis do movimento, quer por sua neutralidade político-partidária, quer por sua postura liberal. Além disso, ninguém colocava em dúvida a sua efetiva participação no movimento, do qual foi um dos primeiros e principais articuladores.

Recorda-se que o presidente do Senado Federal, ao tomar conhecimento da fuga de Goulart, declarou vaga a Presidência da República, tomando posse do cargo, interinamente, de acordo com a Constituição, o presidente da Câmara dos Deputados, que logo em seguida entregou o poder aos chefes militares das três Armas, os quais, em nome do denominado Alto Comando da Revolução, assumiram o controle do País, por quinze dias, período no qual baixaram um Ato Institucional que definia, entre outras coisas, as regras para as eleições presidenciais.

De conformidade com o art. $2^{\circ}$ daquele instrumento, a eleição para presidente e vice-presidente da República seria realizada dois dias após a publicação do Ato, ou seja, no dia 11 de abril de 1964, considerando-se vencedores aqueles escolhidos pela maioria absoluta dos membros do Congresso Nacional, em sessão pública e votação nominal. O presidente e o vice, assim eleitos, exerceriam um mandato-tampão até 31 de janeiro de 1966.

21. Op. cil., p. 368.

22. Apud Glauco Carneiro, op. cit., p. 520. 
O Congresso Nacional, depois de expurgado da maior parte dos parlamentares oposicionistas, através de dispositivo do Ato que permitia cassar mandatos legislativos e suspender direitos políticos pelo prazo de dez anos, foi convidado a referendar o nome de Castello Branco para presidente da República, que, antes de assumir o cargo, passou para a Reserva com o posto de marechal. ${ }^{23}$

\section{O primeiro Ato Institucional}

Com a ascensão de Castello Branco ao poder inaugurou-se uma nova modalidade de intervenção militar na política. De fato, as Forças Armadas, no Brasil, segundo Alfred Stepan, tradicionalmente exerceram o papel de um poder moderador, isto é, as intervenções sempre se caracterizaram por seu caráter transitório, "controlando ou depondo o Executivo, ou até mesmo evitando a ruptura do próprio sistema, especialmente quando isto envolve uma mobilização de novos grupos anteriormente excluídos da participação no processo político" 24

De fato, até 1964, os militares jamais assumiram o poder de forma direta, como representantes do estamento armado. A partir dessa data, porém, verificou-se uma mudança qualitativa no papel das Forças Armadas na política. Com efeito, a partir da derrubada de Goulart, elas não se contentaram mais em exercer a função de simples árbitros nas disputas políticas entre os civis, passando a controlar a máquina estatal diretamente, sem intermediários.

É bem verdade que os militares, a princípio, seguindo o padrão tradicional de intervenção, pretendiam devolver o poder aos civis, assim que fossem atingidos os objetivos básicos do movimento insurrecional, quais sejam, a contenção dos comunistas, o controle da inflação e a execução de reformas políticas e econômicas que permitissem entregar o País saneado aos seus sucessores. Essa intenção veio patenteada no próprio Ato Institucional que, de acordo com o seu art.

23. $\mathrm{O}$ art. 10 do Ato dispunha o seguinte: "No interesse da paz e da honra nacional, e sem as limitações previstas na Constituição, os Comandantes em Chefe, que editam o presente Ato, poderão suspender os direitos políticos pelo prazo de dez (10) anos e cassar mandatos legislativos federais, estaduais e municipais, excluida a apreciação judicial desses atos."

24. Op. cit., p. 51. O autor observa, na p. 52, que o termo poder moderador foi por ele extraido, de forma analógica, da faculdade atribuida ao Imperador pela Constituição Monárquica, no Brasil, de intervir nas disputas políticas em momentos de impasse institucional. 
11, deveria vigorar até 31 de janeiro de 1966, data em que se elegeria o novo presidente e vice-presidente da República.

Os militares de linha dura, contudo, que Stepan classifica de nacionalistas autoritários, opuseram-se tenazmente aos desígnios dos moderados, denominados de internacionalistas liberais pelo autor, que pretendiam devolver, o quanto antes, o poder aos civis. ${ }^{25}$

Não resta dúvida hoje que o Ato Institucional baixado pelo Alto Comando da Revolução apresentava um caráter meramente instrumental e temporário, mesmo porque os políticos e civis que apoiaram o golpe não tinham o menor interesse em manter os militares indefinidamente no poder. Pretendiam os golpistas, valendo-se do Ato, apenas, afastar os esquerdistas do governo e impedir a realização das mudanças estruturais propostas por Goulart e seus aliados, promovendo, em lugar destas, algumas reformas no campo político e no plano econômico, que permitissem a retomada do processo de desenvolvimento.

Para atingir tais objetivos colocou-se nas mãos do presidente da República uma enorme gama de poderes: a competência de enviar emendas constitucionais e projetos de lei ao Congresso Nacional, para apreciação compulsória, no prazo de trinta dias, sob pena de considerá-los aprovados (arts. $3^{\circ} \mathrm{e}$ $4^{\circ}$ ); a iniciativa exclusiva de projetos de lei que criassem ou aumentassem a despesa pública, vedadas as emendas que a onerassem (art. $5^{\circ}$ ); a ampliação das hipóteses de decretação do estado de sítio (art. $6^{\circ}$ ); a suspensão, pelo prazo de seis meses, das garantias constitucionais ou legais de vitaliciedade e estabilidade, para permitir o afastamento de servidores públicos, civis ou militares, nos três níveis federativos, depois de investigação sumária, nos casos de atentado contra a segurança do País, o regime democrático ou a probidade administrativa, sem prejuízo das sanções penais cabíveis, vedado o exame judicial da medida, salvo no tocante aos seus aspectos formais extrínsecos (art. $7^{\circ}$ ); e a faculdade de suspender direitos políticos, por dez anos, e de cassar mandatos legislativos federais, estaduais e municipais, excluída a apreciação judicial do ato (art. 10).

O Preâmbulo explicava a extensão e as finalidades desse instrumento, nos seguintes termos: "O Ato Institucional que é hoje editado pelos Comandantes em Chefe do Exército, da Marinha e da Aeronáutica, em nome da revolução que se tornou vitoriosa com o apoio da Nação, na quase toda a sua totalidade, destina-se a 
assegurar ao novo governo a ser instituido os meios indispensáveis à obra de reconstrução econômica, financeira, política e moral do Brasil, de maneira a poder enfrentar, de modo direto e imediato, os graves e urgentes problemas de que depende a restauração da ordem interna e do prestígio internacional da nossa Pátria (...) Para demonstrar que não pretendemos radicalizar o processo revolucionário decidimos manter a Constituição de 1946 limitando-nos a modificála, apenas, na parte relativa aos poderes do Presidente da República, a fim de que este possa cumprir a missão de restaurar no Brasil a ordem econômica e financeira e tomar as urgentes medidas destinadas a drenar o bolsão comunista, cuja purulência já havia infiltrado não-só na cúpula do governo, como nas suas dependencias administrativas. Para reduzir ainda mais os plenos poderes de que se acha investida a revolução vitoriosa, resolvemos manter o Congresso Nacional, com as reservas relativas aos seus poderes, constantes do presente Ato Institucional"

7. A consolidação do regime

Castello Branco, apesar de sua tendência liberal, não conseguiu fazer prevalecer a idéia da transitoriedade da missão dos militares no front político. Já em julho de 1964, pressionado pelos camaradas da linha dura, que encontravam respaldo junto à oficialidade jovem das Forças Armadas, foi levado a enviar uma emenda constitucional ao Congresso, prorrogando o seu mandato até 15 de março de 1967, a pretexto de que a ampliação do prazo se fazia necessária para a consecução de medidas econômicas de combate à inflação, levadas a efeito por seu governo.

Mais tarde, depois da derrota eleitoral de 1965 -- ocasião em que foram eleitos alguns governadores comprometidos, segundo os militares, com o regime anterior --, Castello Branco viu-se forçado, depois de uma pressão inicial no sentido de anular o pleito, a baixar um novo Ato Institucional, que recebeu o n. 2 (note-se que o primeiro Ato, significativamente, não possuía número, porque os insurretos pretendiam que fosse o único), renovando os poderes excepcionais instituídos no primeiro Ato, pelo Alto Comando da Revolução, que estavam prestes a expirar.

Além da prorrogação dos poderes anteriormente conferidos ao presidente pelo Ato anterior, o de n. 2 estabelecia, ainda, as seguintes medidas: o julgamento de civis pela Justiça Militar, nos casos da prática de crime contra a 
segurança nacional (art. $8^{\circ}$ ); a eleição indireta para a Presidência da República (art. $9^{\circ}$ ); a extensão das prerrogativas presidenciais para a o afastamento de servidores, a cassação de mandatos, a suspensão de direitos políticos e a decretação do estado de sítio e da intervenção federal nos Estados, autorizando-se esta última "para prevenir ou reprimir a subversão da ordem" (arts. 13, 14, 15, 16 e 17); e a extinção dos partidos políticos (art. 18).

A edição desse novo Ato representou, sem dúvida, um aprofundamento do golpe institucional, com o abandono da idéia do exercício transitório do poder. De acordo com Eliézer de Oliveira, esse novo instrumento legal "consagra a hegemonia da 'linha dura' no processo político intramilitar", correspondendo ao fechamento do sistema. ${ }^{26}$

O presidente, de fato, foi obrigado a lançar mão dos atos de exceção por diversas vezes, sobretudo no final de seu mandato. Logrou, porém, manter alguns trunfos, não-obstante as pressões dos oficiais da linha dura ou do denominado sistema, que correspondia à caixa de ressonância militar responsável pelo condicionamento das decisões políticas da cúpula dirigente. Conseguiu, por exemplo, que o novo Ato tivesse uma duração limitada no tempo, ou seja, até 15 de março de 1967, data em que passaria o cargo ao seu sucessor, e também que os dois Atos editados fossem substituídos por uma Constituição, que estabeleceria limites claros e precisos aos poderes revolucionários.

Recorda-se, por oportuno, que, depois desse segundo Ato, foram baixados, na seqüência, mais dois Atos, que receberam os números 3 e 4 . O terceiro deles, datado de 3 de fevereiro de 1966, previa, entre outras coisas, que a eleição dos governadores e vice-governadores seria realizada, de forma indireta, pelas Assembléias Legislativas. O quarto, baixado em 7 de dezembro de 1967, convocava o Congresso Nacional para discutir, votar e promulgar o projeto de Constituição elaborado pela Presidência da República

É interessante lembrar, ainda, que os novos detentores do poder cogitaram, inicialmente, de fazer uma simples Consolidação das Leis Constitucionais Brasileiras, dada a multiplicidade de atos institucionais, atos

26. As Forças Armadas: Politica e Ideologia no Brasil (1964-1969), Petrópolis, Vozes, $2^{\text {: }}$ ed., 1974, p. 64. 
complementares e decretos-leis expedidos pelo governo militar, ao invés de elaborar uma nova Constituição. ${ }^{27}$

Essa idéia inicial, todavia, não vingou, pois o presidente temia "que o fim dos atos implicasse na perempção de preceitos que se mandou ditatorialmente incorporar ao texto constitucional, deixando-se o futuro Presidente desarmado ao mesmo tempo dos poderes de emergência e dos recursos com que se submeter o controle da ação subversiva aos conselhos da Justiça Militar" ${ }^{28}$

Antevendo as dificuldades que o seu sucessor enfrentaria, e procurando disciplinar a ação futura deste, o presidente concluiu pela conveniência de se elaborar um novo texto constitucional, que incorporasse, definitivamente, o instrumental autoritário criado pelos Atos e pela legislação ordinária deles decorrente, com o que, imaginava, seria afastado ou, pelo menos, reduzido o perigo de um novo golpe de Estado. Assim, enviou um projeto pronto e acabado ao Parlamento, que se limitou a referendá-lo, promulgando a nova Carta em 24 de janeiro de 1967.

8. O golpe dentro do golpe

A outorga da Constituição de 1967 , não apazigou os integrantes da linha dura. De fato, antes que a nova Carta lograsse completar dois anos de existência, os temores de Castello Branco fizeram-se realidade, com a deflagração daquilo que Peter Flynn chamou de coup within the coup, ou seja, de golpe dentro do golpe, com a edição, no dia 13 de dezembro de 1968, do Ato Institucional n. 5, instrumento severíssimo, que fechou definitivamente o regime. ${ }^{29}$ Com efeito, dentre outras medidas, o AI n. 5 suspendeu as garantias constitucionais ou legais de vitaliciedade, estabilidade e inamovibilidade de funcionários e magistrados, bem como a de exercício de função por prazo certo (art. $6^{\circ}$ ), sustando também o habeas corpus "nos casos de crimes políticos contra a segurança nacional, a ordem econômica e social e a economia popular" (art. 10). Além disso, autorizou o

27. Cf. Luis Pinto Ferreira, Principios Gerais do Direito Constitucional Moderno, v. I, São Paulo, Revista dos Tribunais, $5^{\text {i }}$ ed., 1971, p. 122; e, também, Wilson Accioli, Instituições de Direito Constitucional, Rio de Janeiro, Forense, 1978, p. 85.

28. Castello Branco, op. cit., p. 552.

29. Op. cit., p. 418 . 
presidente da República a empreender as seguintes providências: suspender direitos políticos pelo prazo de dez anos e cassar mandatos eletivos (art. $4^{\circ}$ ); aposentar, reformar, remover, demitir ou colocar em disponibilidade qualquer servidor público, civil ou militar, federal, estadual ou municipal (art. $6^{\circ}: 1^{\circ}$ ); decretar a intervenção da União nos Estados e Municípios, sem as limitações constitucionais, e o estado de sítio, fixando-lhe a duração (art. $3^{\circ}$ e $7^{\circ}$ ); confiscar bens ilicitamente adquiridos no exercício de cargo ou função pública de qualquer natureza (art. $8^{\circ}$ ).

O fechamento do regime foi consolidado pela edição de outros diplomas de exceção, os quais, em suma, dispunham sobre o seguinte: o Ato Institucional n. 6 , de $1^{\circ}$ de fevereiro de 1969, diminuiu para onze o número de ministros do Supremo Tribunal Federal, atribuindo o julgamento de civis à Justiça Militar, no caso de crimes contra a segurança nacional ou as instituições militares; o Ato Institucional n. 7, de 26 de fevereiro de 1969, estabeleceu um teto para os subsídios dos legisladores estaduais e municipais, suspendendo as eleições parciais para cargos executivos e legislativos da União, dos Estados, dos Territórios e dos Municípios; o Ato Institucional n. 8, de 2 de abril de 1969, atribuiu ao Executivo, nos três níveis político-administrativos, a competência de implantar extensa reforma administrativa, por decreto, observados os princípios adotados para a Administração Federal; o Ato Institucional n. 9, de 25 de abril de 1969, modificou o art. 157, $\S 1^{\circ}$, da Constituição de 1967, para facilitar a execução da reforma agrária; o Ato Institucional n. 10, de 16 de maio de 1969, ampliou as consequiências da suspensão de direitos políticos e da cassação de mandatos, impondo sanções complementares; o Ato Institucional n. 11, de 14 de agosto de 1969, estabeleceu a uniformização dos mandatos municipais em curso, extinguindo a Justiça de Paz eletiva, cujos juízes passaram a ser nomeados pelos governadores dos Estados e pelo prefeito do Distrito Federal, por três anos, admitida uma recondução; o Ato Institucional n. 12, de 31 de agosto de 1969, determinou que as funções do presidente Costa e Silva, acometido por grave enfermidade, fossem exercidas por uma Junta Militar, integrada pelos ministros da Marinha, do Exército e da Aeronáutica; o Ato Institucional n. 13, de 5 de setembro de 1969, estabeleceu a pena de banimento para o brasileiro que se tornasse "inconveniente, nocivo ou perigoso à Segurança Nacional"; o Ato Institucional n. 14, de 5 de setembro de 1969, introduziu na Constituição a pena de morte nos "casos de Guerra Externa, Psicológica Adversa, ou Revolucionária ou Subversiva" bem como a de "perdimento de bens por danos causados ao Erário"; o Ato Institucional n. 15, de 9 de setembro de 1969, prorrogou os prazos para as 
eleições municipais, fixando novas datas e regras; o Ato Institucional n. 16, de outubro de 1969, decretou a vacância dos cargos de presidente e vice-presidente da República, em virtude da doença de Costa e Silva, estabelecendo normas para a sucessão, ao mesmo tempo em que suspendia a vigência do dispositivo constitucional que previa as regras de substituição do chefe do Executivo, nas hipóteses de impedimento deste ou de vaga do respectivo cargo; finalmente, o Ato Institucional n. 17, de 14 de outubro de 1969, facultava ao presidente da República a transferência para a reserva, por tempo determinado, dos militares que atentassem contra a "coesão das Forças Armadas" Todos os Atos Institucionais previam, em dispositivo próprio, que as medidas tomadas com fundamento neles, assim como os respectivos efeitos, estavam isentos de apreciação judicial.

Para conferir uma aura de legitimidade ao sistema legal por eles engendrado, os militares foram obrigados a reformular a Carta de 1967. Isso foi feito aproveitando-se o recesso do Legislativo decretado pelo presidente Costa e Silva, por meio do Ato Complementar n. 38, de 13 de dezembro de 1968, com fundamento no art. $2^{\circ}$ do AI n. 5. Fechado o Congresso Nacional, a Junta Militar que substituiu Costa e Silva, impedido por razões de saúde, outorgou a Emenda Constitucional n. 1, em 17 de outubro de 1969, colocando em vigor uma nova Constituição, que nada mais era do que a de 1967, à qual se incorporou os instrumentos excepcionais editados durante a vigência desta. ${ }^{30}$

Essa Carta, é interessante notar, apresentava um caráter sui generis, consistente em estar subordinada a uma espécie de norma fundamental (Grundnorm) kelseniana, eis que sua validade estava condicionada, por força de seu art. 183, ao AI n. 5 e demais atos posteriormente baixados, que continuavam em plena vigência. ${ }^{31}$ $\mathrm{Na}$ realidade, essa situação se manteve mesmo depois que a Emenda Constitucional n. 11, de 13 de outubro de 1978, revogou o referido instrumento e todos os subseqüentes, visto que o fez apenas naquilo em que contrariassem a Constituição,

30. Sobre o impedimento de Costa e Silva, v. Carlos Chagas, 113 Dias de Angístia: Impedimento e Morte de um Presidente, São Paulo, L\&PM, 1979.

31. Para Hans Kelsen, Teoria Pura do Direito, Coimbra, Armênio Amado, $3^{\text {a }}$ ed., 1974, p. 264, a norma fundamental "é a fonte comum de validade de todas as normas pertencentes a uma e mesma ordem normativa" Nesse sentido, observa-se que o art. 183 da CF de 1969 dispunha o seguinte: "Continuam em vigor o Ato Institucional n. 5, de 13 de dezembro de 1968, e os demais posteriormente baixados. Parágrafo único: O Presidente da República, ouvido o Conselho de Segurança Nacional, poderá decretar a cessação da vigência de qualquer desses Atos ou dos dispositivos que forem considerados desnecessários" 
ressalvando as medidas já tomadas com base nos mesmos, as quais ficavam isentas de apreciação judicial. ${ }^{32}$

O arcabouço legal autoritário, lembra-se, foi desmontado paulatinamente, constituindo a edição da referida EC n. 11/78 a primeira etapa desse processo, na medida em que se introduziu na Carta de 1969, em substituição aos atos institucionais e complementares, ao lado do tradicional Estado de Sítio, o Estado de Emergência e as Medidas de Emergência, instrumentos que permitiam ao presidente da República suspender algumas garantias constitucionais "para preservar ou, prontamente, restabelecer, em locais determinados e restritos, a ordem pública ou a paz social, ameaçadas ou atingidas por calamidades ou graves perturbações" ou, ainda, para impedir ou repelir atividades subversivas. ${ }^{33} \mathrm{~A}$ volta à plenitude do Estado de Direito, como se sabe, somente foi alcançada com a promulgação da Constituição de 1988.

São Paulo, agosto de 1998.

32. Art. $3^{\circ}$ da EC n. 11/78: "São revogados os atos institucionais e complementares no que contrariarem a Constituição Federal, ressalvados os efeitos dos atos praticados com base neles, os quais estão excluídos de apreciação judicial".

33. V. arts. 155,156 e 157 da Constituição de 1969. 